\title{
GALERI SENI BARANG DAUR ULANG
}

\author{
Geoffrey Gregorio ${ }^{1)}$, Tony Winata ${ }^{21}$ \\ 1)Program Studi S1 Arsitektur, Fakultas Teknik, Universitas Tarumanagara, geoffrey.315160064@stu.untar.ac.id \\ ${ }^{2)}$ Program Studi S1 Arsitektur, Fakultas Teknik, Universitas Tarumanagara, tonywinata@ft.untar.ac.id
}

Masuk: 14-07-2020, revisi: 01-08-2020, diterima untuk diterbitkan:05-09-2020

\begin{abstract}
Abstrak
Kawasan Tambora merupakan kawasan terpadat di Jakarta, yang mayoritas penduduknya menengah kebawah.Hal ini ditunjukan dengan sebagian besar rumah-rumah yang ada dikawasan ini tergolong kecil ke sedang dan juga kualitas kehidupan masyarakat di Tambora . Ditengah padatnya wilayah ini tidak ada area terbuka yang menjadi wadah bagi mereka untuk berinsteraksi antar sesama.Akibatnya banyak sekali penduduk yang menghabiskan waktu luangnya diluar rumah untuk berinteraksi dan bersosialisasi, namun hal ini menyebabkan kemacetan dan juga kebisingan yang cukup mengganggu warga lainnya. Permasalahan ini akan dijawab dengan produk arsitektur berupa wadah yang menjadi tempat bagi mereka untuk berinteraksi,melepas penat dan stress, menghabiskan waktu luangnya dan melakukan berbagai kegiatan tanpa membedakan golongan manapun dan terbuka untuk umum tanpa dipungut biaya. Di dalam bangunan ini nantinya akan dimasukkan beberapa program seperti pameran, kelas daur ulang, area makanan, dan hiburan lainnya, yang ditentukan berdasarkan karakteristik dari wilayah Tambora ini.Bangunan ini juga mempunyai area komersil seperti toko retail sovenir dan toko material. Proyek ini di design berdasarkan metode perancangan re-image oleh John Zeisel, analisis dan riset pribadi yang berfokus pada fungsi dan massa bangunan agar bisa memberikan dampak positif bagi lingkungan Kawasan Tambora.
\end{abstract}

\section{Kata kunci: Area Terbuka; Daur Ulang; Pameran}

\begin{abstract}
Tambora area is the most populous area in Jakarta, the majority of the population is middle-low. This is indicated by the majority of the houses in this area classified as small to medium and the quality of life in Tambora. In the midst of this dense area there is no open area which is a place for them to interact among themselves. This causes many of the peoples spent their spare time out of their house to interact and socialize with others, but it makes traffic jam and noises. This problem will be answered with architectural products in the form of a container that becomes a place for them to interact and carry out various activities without distinguishing any groups and open to the public free of charge. In this building, a number of programs will be included such as exhibitions, recycling classes, food and other entertainment areas, which are determined based on the characteristics of the Tambora region. This building also has commercial area like souvenier and material store. This project is designed based on John Zeisel's re-image design method, analysis and personal research that focuses on the function and mass of the building in order to have a positive impact on the environment of the Tambora Area.
\end{abstract}

Keywords: Exhibition; Open area; Recycle 


\section{PENDAHULUAN}

Sebuah kota mengalami perkembangan karena terjadi peningkatan gaya hidup yang disebabkan oleh peningkatan kebutuhan manusia yang tinggal di dalamnya. Hal ini juga berlaku bagi kota Jakarta. Jakarta terus berkembang dan diiringi dengan persaingan ekonomi yang yang cukup ketat menyebabkan masyarakat menghabiskan sebagian besar waktunya untuk belajar untuk kemudian bekerja demi memenuhi kebutuhan hidup yang terus meningkat sehingga menyebabkan masyarakat memiliki rutinitas yang sama hampir setiap hari. Hal ini membuat Jakarta harus memperhatikan kualitas hidup masyarakatnya. Salah satu usaha yang dapat menjawab permasalah tersebut adalah dengan menyediakan tempat ketiga untuk dijadikan sebagai wadah untuk melepas penat dan stress akibat beban pikiran dalam dunia kerja, serta bersosialisasi karena pada dasarnya manusia merupakan mahkluk sosial yang membutuhkan interaksi sosial dengan sesamanya. Namun, perkembangan zaman dan teknologi yang diikuti dengan perubahan cara berperilaku membuat manusia menjadi individualis. Hal ini dapat dibuktikan dengan salah satu survei yang dilakukan oleh Search Institute's Survey of Youth Assets, bahwa sebesar $65 \%$ orang merasa tidak nyaman untuk bersosialisasi dengan yang berbeda latar belakang.

Third place hadir sebagai ruang publik yang bersifat netral agar mampu mewadahi menjawab kebutuhan akan interaksi sosial untuk bertukar pikiran, melepas beban pikiran dan juga stress akibat padatnya aktivitas di sekolah, kampus, tempat kerja, dan lain-lain tanpa merasa canggung untuk berinteraksi meskipun berbeda latar belakang. Lokasi yang strategis dan juga yang sering menjadi lintasan banyak orang bepergian dari rumah ke tempat kerja, sekolah, atau kampus dan sebaliknya, serta tidak terlalu jauh dari tempat - tempat tersebut menjadi kriteria utama dalam pemilihan kawasan dan tapak perancangan karena jarak dan waktu menjadi elemen penting yang harus dipertimbangkan agar nantinya lokasi dari third place yang akan dirancang dapat dengan mudah dijangkau oleh penggunanya.

\section{Isu Kawasan}

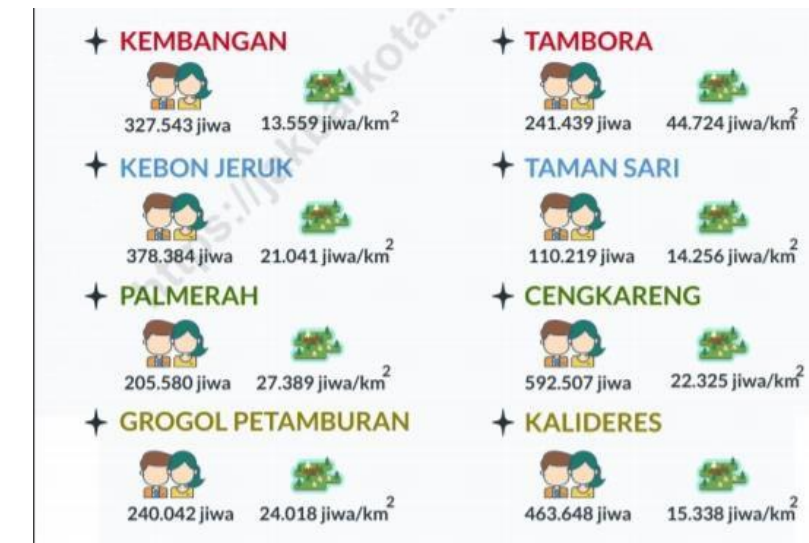

Gambar 1. Tingkat Kepadatan Penduduk Kota Jakarta Barat

Sumber: jakbarkota.bps.go.id (25/01/2020)

Berdasarkan berita pada poskota.id (25/01/2020) diberitakan bahwa Kawasan Tambora adalah Kawasan terpadat di DKI Jakarta, dan juga rata-rata penduduk di Kawasan tersebut berekonomi menengah kebawah. Berdasarkan hasil survey, penulis menemukan banyak sampah-sampah berserakan sehingga menimbulkan bau tak sedap. Hal ini bisa menjadi peluang jika sampah-sampah itu bisa diolah menjadi bahan daur ulang ataupun makanan ternak dan pupuk, secara tidak langsung ini akan memberikan pendapat tambahan bagi pedagang disana. Hanya wadah untuk mereka mendaur ulang sisa-sisa sampah yang tiadk mereka punya. banyak juga pedagang yang melanggar aturan karena berjualan di pedestrian yang seharusnya menjadi hak pejalan kaki. Akibatnya banyak orang-orang yang berjalan di jalan kendaraan yang memakan 1 jalur kendaraan tidak bisa dilewati oleh kendaraan, sehingga terjadi kemacetan yang sangat 
panjang, mengingat Tidak hanya sampai disana, ada permasalahan lain yaitu, tidak ada area terbuka di kawasan ini. Hal ini berdampak sangat serius karena di usia anak-anak yang masih muda, mereka membutuhkan tempat bermain yang layak. Akibatnya sering terjadi kecelakaan yang menimpa anakanak yang sering berlari-larian di jalan ataupun yang bermain bola. Maka dari itu, Third place yang akan dibangun di daerah Jembatan Lima diharapkan bisa menjawab permasalahan-permasalahan diatas. Tidak hanya menjawab kebutuhan kawasan melainkan juga bisa menjadi wadah tempat untuk mereka bersosialisasi, sehingga dapat memberikan dampak pengaruh positif terhadap kawasan

\section{Kondisi Kawasan}

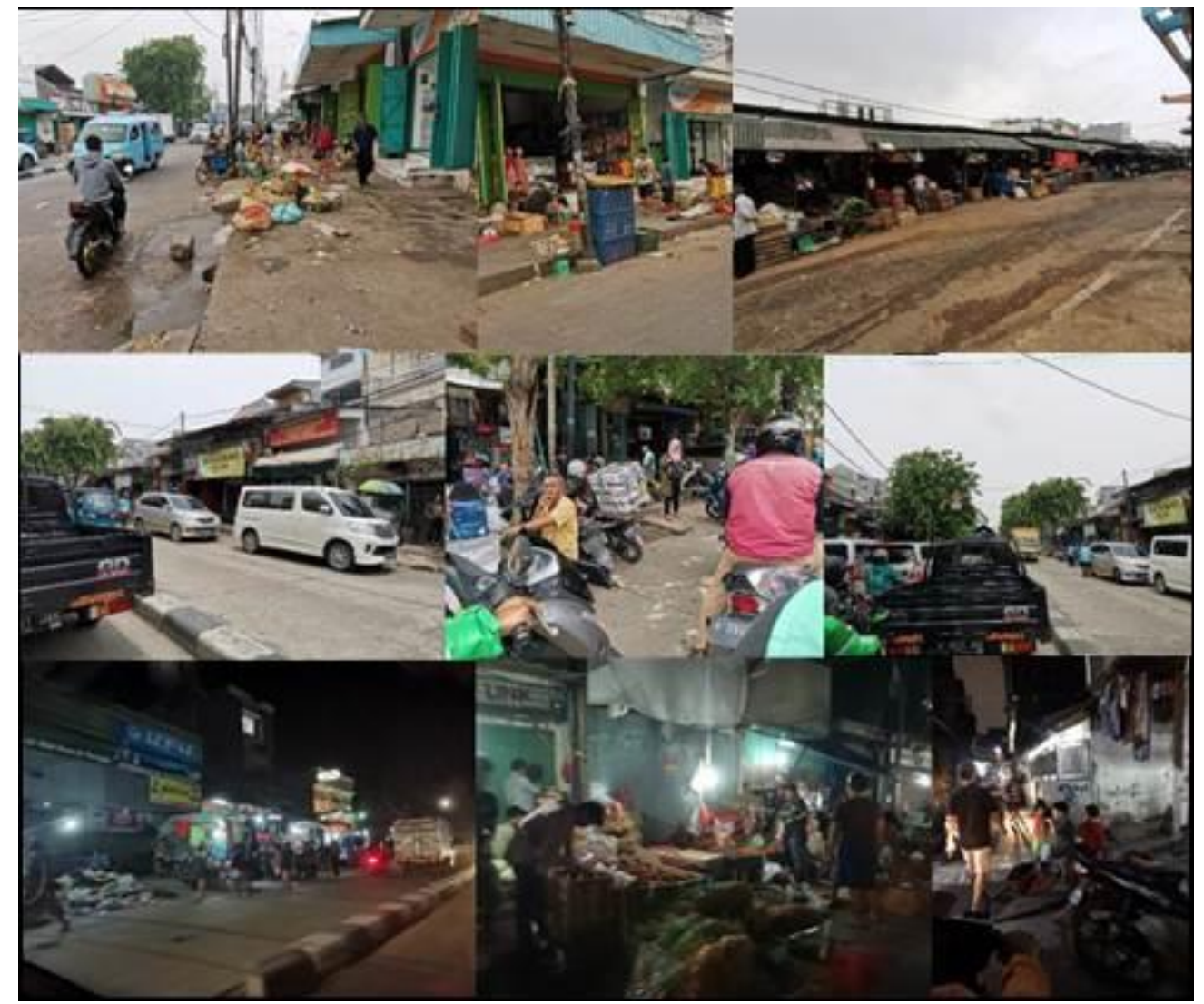

Gambar 2. Kondisi sekitar tapak

Sumber : dokumentasi pribadi

Di sepanjang jalan KH. Moh. Mansyur ditemukan banyak sekali sampah-sampah berserakan di trotoar sisa dari pasar malam, mengakibatkan bau tak sedap dan juga mengganggu pengguna jalan pedestrian yang hendak lewat. Banyaknya kendaraan yang parkir sembarangan di pinggir jalan yang seharusnya bukan untuk parkir, mengakibatkan kemacetan yang cukup panjang, ditemukan juga beberapa toko yang meletakan barang jualannya di trotoar yang seharusnya untuk pedestrian. Pada malam hari, ditemukan juga warga-warga yang tinggal disana sering nongkrong, mengobrol di depan rumah atau bahkan di gang-gang jalan, yang menjadi masalah adalah mereka membuat kebisingan yang mengganggu warga lain yang ingin istirahat, mereka bisa nongkrong hingga pukul 12 malam bahkan lebih. Anak-anak juga sering bermain gadget diluar rumah hingga larut malam, mereka kehilangan hak bermainnya karna tidak adanya wadah untuk mereka bermain di sekitar Jembatan Lima. Pedagang pasar malam tidak mempunyai tempat beristirahat. 


\section{KAJIAN LITERATUR}

\section{Definisi Third place}

Third place merupakan "sharing place" yang merupakan dialog antara ruang privat dan juga publik. Menurut Ray Oldenburg (1989) third place didefiniskan sebagai "the great, good place" yang merupakan wadah untuk membina komunitas dan komunikasi diantara orang-orang diluar dari rumah yang disebut sebagai first place dan tempat bekerja yang disebut sebagai second place. Third place erat kaitannya dengan produksi ruang sosial yang memiliki 3 konsep utama seperti teori menurut Henri Lefebvre pada gambar berikut.

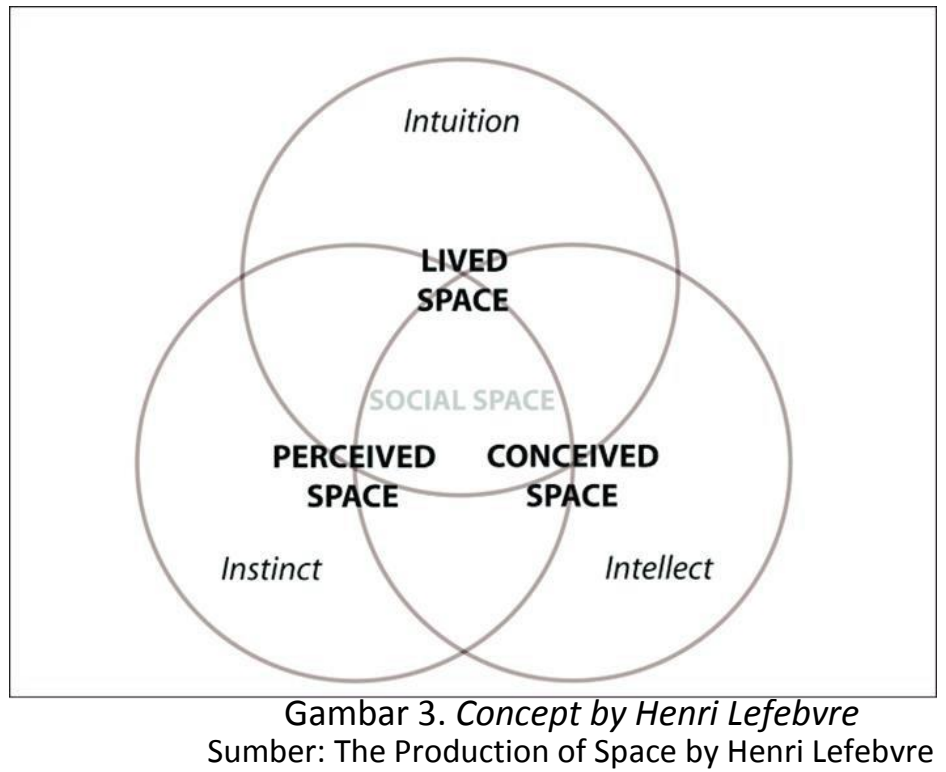

Tiga konsep oleh Henri Lefebvre terdiri dari:

\section{a. Perceived Space}

Ruang yang memiliki aspek perspektif yang dapat ditangkap oleh panca indera yang terdiri dari segala sesuatu yang bisa diserap oleh panca indera. Tidak hanya dilihat, tapi juga didengar, dicium, disentuh, dan dirasa. Aspek ini berkaian dengan materialist "elemen" yang pada akhirnya menyusun sebuah "ruang".

\section{b. Lived Space}

Dimensi ketiga dari produksi ruang adalah pengalaman hidup di dalam ruang. Dimensi ini menunjukkan dunia seperti yang dialami oleh manusia dalam praktek kehidupan sehari-hari. Pada titik ini, Lefebvre menegaskan bahwa realitas hidup, pengalaman praktis, tidak akan selesai melalui analisa teoritis karena akan selalu terdapat surplus, sisa, atau residu berharga yang tak teranalisis atau terjelaskan yang terkadang hanya dapat dinyatakan melalui cara- cara artistic

c. Conceived Space

Ruang tidak dapat dipersepsi tanpa memahaminya terlebih dahulu di dalam pikiran. Merangkai berbagai elemen untuk membentuk suatu "kesatuan yang utuh" yang kemudian disebut sebagai "ruang" merupakan tindakan pikiran dalam memproduksi pengetahuan.

\section{Karakteristik}

Third place harus memilki sifat flexibility, openness, dan contextuality.

\section{a. Flexibility}

Kebebasan dalam bagaimana menempati ruang dengan kemungkinan terciptanya hybrid programming. Hybrid programming sangatlah mungkin terjadi dalam perancangan third place demi terciptanya wadah yang dapat menampung lebih dari satu aktifitas.

\section{b. Openness}

Terdiri dari dua aspek yaitu fisik (view, void, accessibility, porosity), dan non fisik (programming, placeness, playfulness). Openness berarti bersifat inclusiveness, equal, dan permeable. Dengan 
adanya sifat ini, third place akan mudah diakses oleh siapapun dan menjadi a wolrd of stranger dimana semua orang bebas berinteraksi dan bertukar informasi satu sama lain.

\section{c. Contextuality}

Third place harus dapat menjawab kebutuhan lingkungan sekitar dan memberikan dampak positif kepada sekitarnya serta terkait dengan identitas lokal, kehidupan sehari-hari, budaya, dan sejarah setempat.

Third place merupakan tempat yang dapat memenuhi kebutuhan individual. Kebutuhan yang dimaksud dapat berupa kebutuhan akan interaksi sosial, kebutuhan akan kegiatan yang berkaitan dengan hal-hal kreatif, maupun yang berkaitan dengan kesehatan. Third place menurut Ray Oldenburg (1997) memiliki karakteristik yaitu bersifat netral yang berarti third place tidak terikat unsur finansial, politik, hukum, dan lain - lain. Bersifat setingkat berarti tidak adanya hierarki yang memandang latar belakang dan status sosial. Memiliki kegiatan utama berupa percakapan antar orang, tempatnya mudah diakses, memiliki pengunjung tetap, dan bersifat playful.

\section{Open Architecture}

Desain dalam menciptakan third place akan sangat berpengaruh dalam mendorong adanya interaksi antar kelompok yang mungkin terputus satu sama lain. Oleh karena itu, third place erat kaitannya dengan open city, open society, dan open architecture. Open city mengacu pada usaha arsitek dan juga urban designer untuk menerjemahkan ide desain. Selanjutnya, open society berarti memungkinkan masyarakat untuk bisa berkumpul dan beriteraksi satu sama lain. Sedangkan open architecture mengacu pada keterbukaa desain yang dapat menyesuaikan dengan perkembangan zaman yang kini telah berorientasi kepada teknologi sehingga memungkinkan adanya ahi dari bidang lain yang terlibat dalam proses perancangan. Prinsip open architecture dimaksudkan agar dalam sebuah perancangan tak hanya memikirkan sebuah struktur, namun juga memikirkan perilaku dan juga kebutuhan manusia atau penggunanya nanti, sehingga aspek detail sangatlah penting. Sebagai contoh, penyediaan teknologi yang sudah lazim saat ini adalah wi-fi gratis. Wi-fi gratis akan mengubah banyak tempat menjadi titik pertemuan dan menyatukan orang-orang dari berbagai usia. Selain itu, pemesanan meja seperti di cafe dan restoran, pendaftaran menjadi member di sebuah fitness center juga telah bisa dilakukan secara online.

Open architecture juga memiliki kaitan yang erat dengan multiprogram atau cross programming (private in society), passive coding, area publik - servis yang jelas, situasi pedestrian yang menyesuaikan bangunan, serta social impact. Di Indonesia sendiri, konsep open architecture yang diterapkan pada perancangan harus memperhatikan beberapa aspek seperti community (kerja sama dan gotong royong), living together, richness of tribe, place for expression, dan local material. Aspek aspek ini harus tercermin pada hasil perancangan yang menerapkan konsep open architecture.

\section{Open Space}

Open Space merupakan ruang yang direncanakan karena kebutuhan akan tempat- tempat pertemuan dan aktivitas bersama di udara terbuka. Dengan adanya pertemuan bersama dan relasi antara orang banyak, kemungkinan akan timbul berbagai macam kegiatan di ruang umum tersebut. Sebenarnya ruamg terbuka merupakan salah satu jenis dari ruang umum. (Budiharjo \& Sujarto, 2005, p. 89)

Menurut Rustam Hakim merupakan suatu tempat atau area yang dapat menampung aktivitas tertentu manusia, baik secara individu atau secara kelompok (Hakim, 2012, p. 12). Secara teoritis pengertian Open Space adalah :

a. Merupakan ruang yang terdiri dari ruang keras (hard space) dibatasi oleh dinding arsitektural serta digunakan untuk aktfitas sosial dan ruang lunak (soft space) didominasi oleh lingkungan alam seperti kebun, jalur hijau, dan taman (Trancik, Finding Lost Space: Theories of Urban Design, 1986, pp. 60-86)

b. Merupakan ruang 3 dimensi yang dibatasi oleh berbagai elevasi ketinggian seperti bangunan dan pohon (Krier, 1979, p. 63) 
Dari beberapa pendapat ahli di atas, dapat disimpulkan bahwa ruang terbuka adalah sebuah ruang yang terdiri dari perkerasan maupun penghijauan yang dapat menampung berbagai aktivitas manusia didalamnya.

\section{Ruang Publik}

Ruang publik adalah ruang yang berfungsi untuk tempat menampung aktivitas masyarakat, baik secara individu maupun secara kelompok, dimana bentuk ruang publik ini sangat tergantung pada pola dan susunan massa bangunan (Rustam Hakim,1987).Menurut Carr dkk (1992), tipologi ruang publik penekanan kepada karakter kegiatannya, lokasi dan proses pembentuknya. Carr dalam Carmona, et al (2003) mengemukakan adanya keterlibatan pasif (passive engagement) dan aktif (active engagement) dalam pemanfaatan ruang publik. Kedua bentuk pengalaman ini terjadi sebagai akibat adanya proses interaksi tersebut, dimana pengguna ruang publik dapat melakukan interaksi dengan cara yang berbeda. Ruang sebagai wadah harus mampu menyediakan lingkungan yang kondusif bagi terpenuhinya syarat interaksi, yaitu memberi peluang bagi terjadinya kontak dan komunikasi sosial. Interaksi sosial dapat terjadi dalam bentuk aktivitas yang pasif seperti sekedar duduk menikmati suasana atau mengamati situasi dan dapat pula terjadi secara aktif dengan berbincang bersama orang lain membicarakan suatu topik atau bahkan melakukan kegiatan bersama.

Ruang Publik Secara Ideal Menurut Carr, ruang publik harus memiliki tiga hal yaitu responsif, demokratis, dan III - 2 bermakna. Responsif dalam arti ruang publik adalah ruang yang dapat digunakan untuk berbagai kegiatan dan kepentingan luas yang memiliki fungsi lingkungan hidup. Artinya ruang publik dapat digunakan oleh masyarakat umum dari berbagai latar belakang sosial, ekonomi, dan budaya serta akses bagi berbagai kondisi fisik manusia. Memiliki arti ruang publik harus memiliki tautan antara manusia, ruang, dan dunia luas dengan konteks sosial. Dengan kata lain, ada sistem pemaknaan dalam ruang publik.

\section{METODE}

Metode yang digunakan dalam proses perencanaan dan perancangan Scavenger art gallery dimulai dari survey ke lapangan untuk melihat kondisi sekitar dan juga permasalahan yang ada di lapangan.Dilanjutkan dengan pengumpulan data dari internet mengenai data kependudukan dan wilayah.Selanjutnya dilakukan analisis dengan menerapkan teori re-image untuk menghasilkan desain perancangan.

\section{Metode Re-image by John Zeisel}

Dari kajian teori pada bab sebelumnya, didapat berbagai macam kriteria-kriteria umum untuk membantu merancang third place. Kriteria - kriteria tersebut diambil dari teori - teori terkait open architecture for the third place dan penelitian sejenis lainnya. Kriteria - kriteria yang telah didapat kemudian diseleksi dengan menggunakan metode re-image oleh John Zeisel, yang lebih berkonsentrasi pada lingkungan dan interaksi antar perilaku (Zeisel, J. (1987) Inquiry by Design: Tools for Environment-Behavior Research. New York and Melbourne: Press Syndicate of the University of Cambridge. 


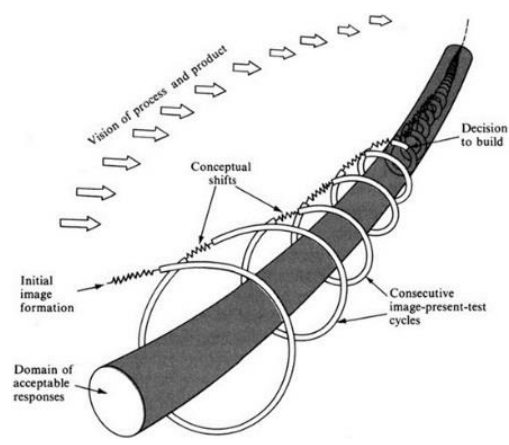

Gambar 4. Concept by Henri Lefebvre

Sumber: The Production of Space by Henri Lefebvre

Zeisel yang menyebutkan bahwa proses berpikir seperti sebuah spiral (sesuatu yang berputarputar) yang menuju satu penajaman. Zeisel menyebut desain sebagai aktivitas proses berpikir yang kompleks dengan tiga aktivitas dasar yaitu imaging-presenting-testing dengan didahului oleh suatu knowledge. Penajaman spiral tersebut pada akhirnya terhenti ketika perancang memutuskan untuk berhenti, entah itu disebabkan oleh batas waktu atau memang perancangnya sendiri merasa sudah cukup. Imaging merupakan tahap dimana perancang menawarkan sesuatu yang baru memberikan kriteria seperti apakah arsitektur kedepannya. Presenting merupakan hasil dari kriteria yang diterapkan pada rancangan. Sedangkan testing merupakan evaluasi atas desain yang telah dihasilkan berdasarkan kriteria-kriteria. Yang keseluruhannya dilakukan berdasarkan data - data yang ada.

Metode John Zeisel kemudian diadaptasi ke dalam diagram alur pikir desain yang menunjukkan proses alur berpikir yang dimulai dari pencarian data terkait studi teori, literatur, dan juga identifikasi permasalahan \& persoalan sebagai awalan untuk melakukan tahap imaging. Kemudian diikuti oleh analisis dan pengolahan data yang akan menghasilkan kriteria desain yang akan dibuat sebagai bentuk dari tahap presenting. Dari hasil analisa yang sudah dilakukan, maka akan menghasilkan suatu transformasi dan hasil desain. Hasil desain itu kemudian akan memasuki tahap testing untuk dievaluasi guna mengetahui apakah tujuan yang ingin dicapai sudah terlaksana atau belum untuk kemudian dapat menjadi pembelajaran dan literatur bagi proyek - proyek baru yang serupa.

\section{DISKUSI DAN HASIL}

\section{Analisa Tapak}

Analisa kegiatan di sekitar tapak mendasari program ruang yang nantinya akan dimasukan ke dalam proyek bangunan. Analisa diperkuat dengan identifikasi masalah dan juga analisa kawasan. Dari hasil analisa tersebut maka didapatkan program, exhibition, food and beverages, workshop, office, parks, dan service area.
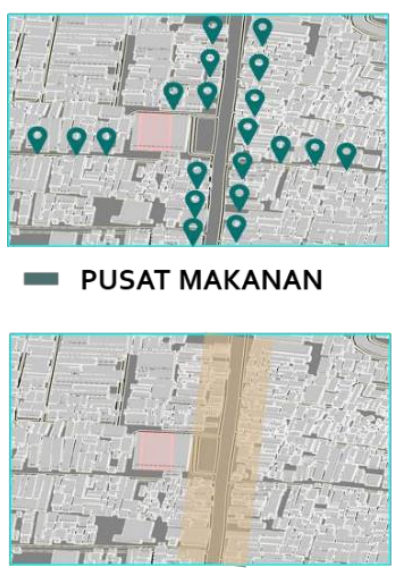

- PASAR MALAM

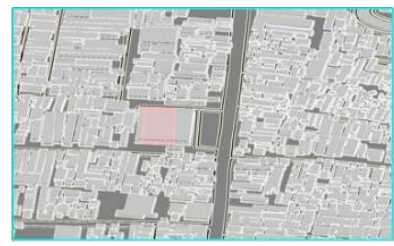

- AREA HIJAU

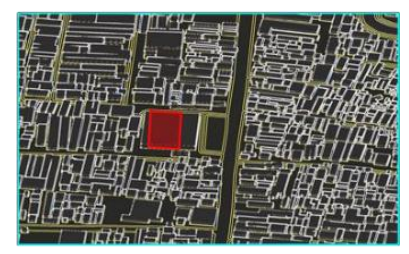

- TINGKAT KEPADATAN

Gambar 5. Skema Gubahan Massa

Sumber: Dokumen Pribadi 
Zoning bangunan diatur dengan berdasarkan kondisi tapak dan jalan, massa diarahkan kearah persimpangan jalan KH Moh Mansyur dan jalan sawah lio sebagai bentuk kontekstual terhadap jalan. Area yang bersifat bising diletakan jauh dari area pemukiman agar mengurangi bising yang dapat mengganggu kenyamanan warga sekitar. Taman dan tempat retail makanan diletakkan di bagian basement untuk mereduksi tingkat kebisingan. Taman diletakkan di tengah berfungsi sebagai pengikat antar massa agar menjadi satu bagian yang saling terhubung.

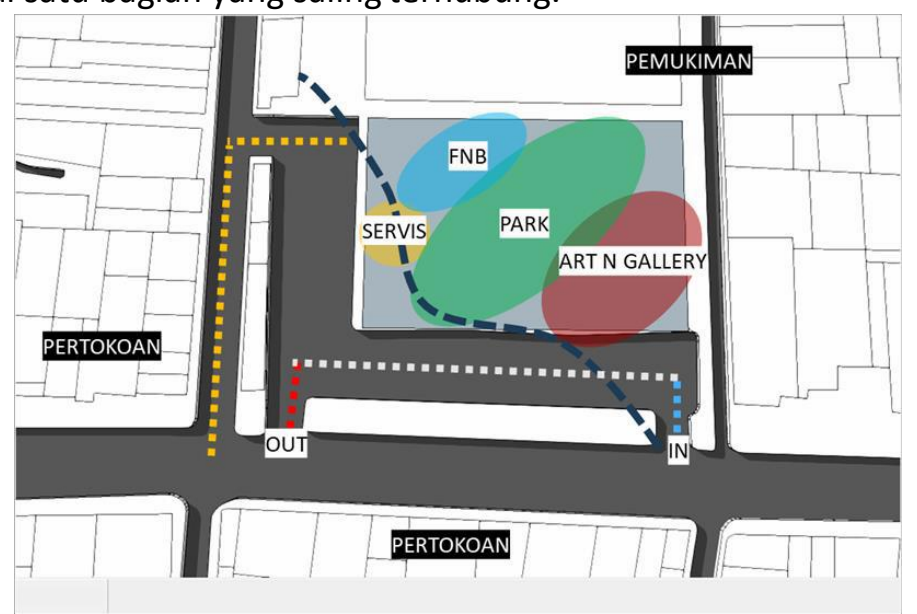

Gambar 6. Skema Gubahan Massa Sumber: Dokumen Pribadi

Sirkulasi pengunjung dibedakan dengan jalur servis yang terletak dibelakang agar tidak mengganggu pengujung dari arah lobi utama. Akses masuk ke tapak dapat diakses melalui 3 arah, utara timur dan selatan. Jalur pedestrian diutamakan dari jalan utama yang lebih ramai.Disediakan beberapa tempat parkir untuk kendaraan roda 4 dan 2 bagi pengunjung.

\section{Gubahan Massa}

1

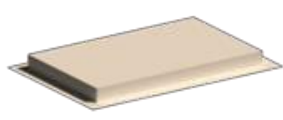

4

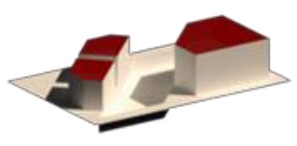

2

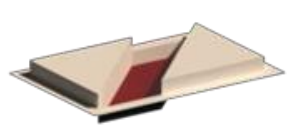

5

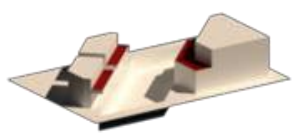

3

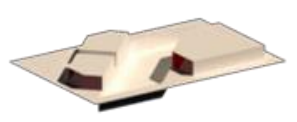

6

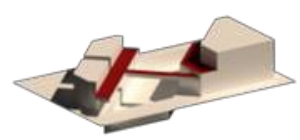

Gambar 7. Skema Gubahan Massa

Sumber: Dokumen Pribadi

Tahap pertama dari sebuah bentuk solid. Lalu kita membuat sebuah space di tengah yang berorientasi pada jalan sekunder KH Moh Mansyur.Tahap ketiga kita memaksimalkan peluang akses terbesar hingga terkecil pada sekitar tapak, dengan total jumlah ada 3 akses masuk dan keluar pada bangunan. Akses untuk keperluan servis dibedakan dari akses pengunjung. Tahap keempat leveling massa bangunan sesuai kebutuhan program ruang, ketinggian massa diatur dari luasan kebutuhan ruangnya. Dan agar bisa dapat pencahayaan maksimal, kita memainkan ketinggian bangunan.Tahap kelima Substraction terhadap sebagian massa untuk menangkap cahaya alami dan menciptakan ruang terbuka. Ruang terbuka menjadi salah satu faktor utama dari bangunan ini sehingga akan banyak aktifitas semi outdoor. Tahap terakhir sebuah bridge dan canopy yang menghubungkan semua nya jadi satu kesatuan. 


\section{Denah}

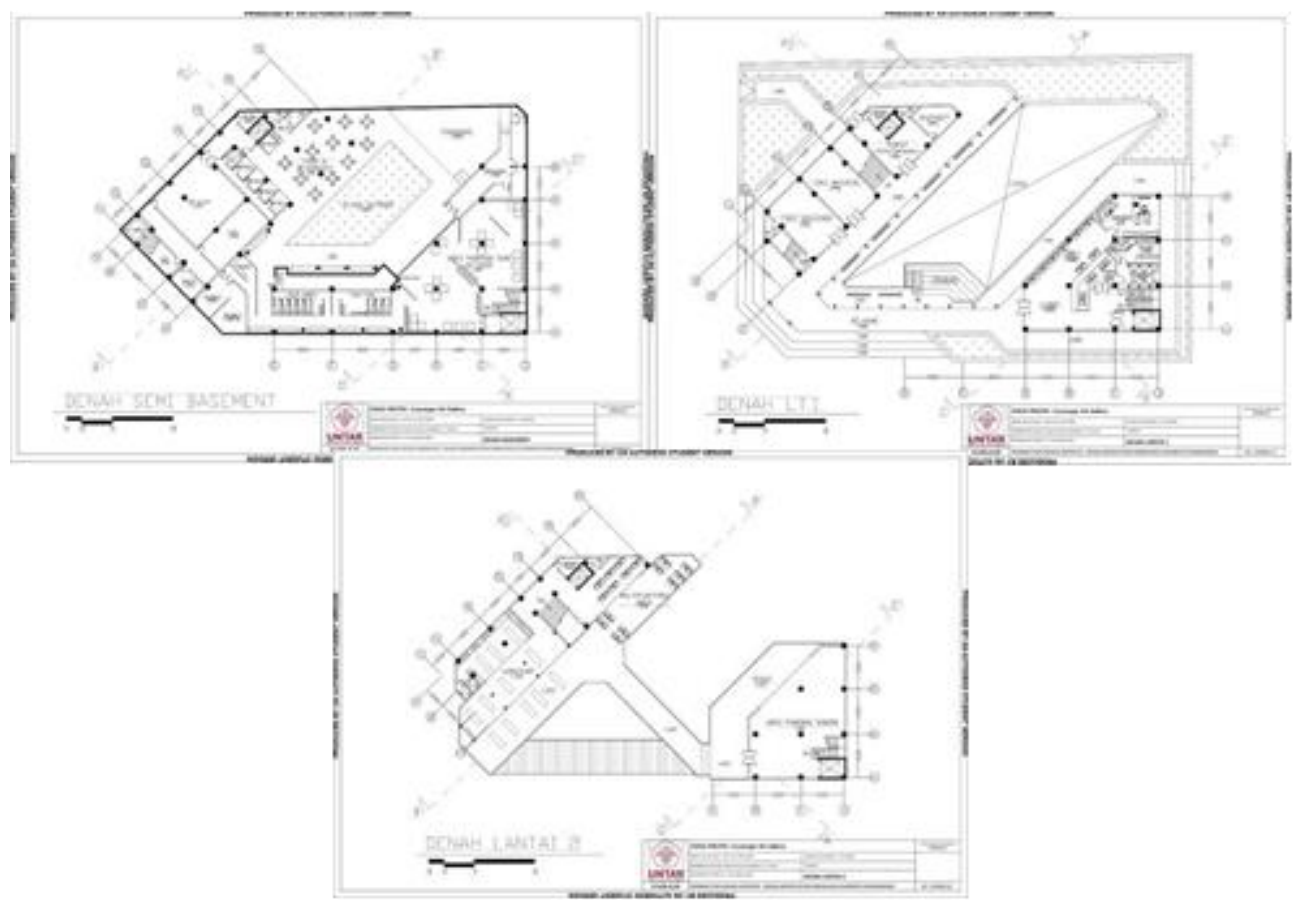

Gambar 8. Skema Gubahan Massa

Sumber: Dokumen Pribadi

Pada lantai basement diletakan ruang-ruang servis dan juga terdapat area pameran indoor, playground, panggung, area reteil makanan. Di lantai dasar terdapat main lobby, area drop off, kantor pengelola, toko souvenir, toko material dan juga area loading barang. Pada lantai 2 ada area pameran utama yang bersifat semi outdoor juga kelas workshop yang mengelola barang untuk di daur ulang, dan ruang multifungsi yang bisa digunakan untuk rapat, seminar dan berbagai acara bersama.

\section{Deskripsi Desain}

Setelah melalui proses perancangan dan berbagai analisis maka dihasilkanlah desain bangunan Scavenger Art Gallery. Judul proyek ini diambil dari kata scavenger yang artinya adalah barang rongsokan/usang yang sudah tidak terpakai lagi. Dikarenakan kebiasaan penduduk Kawasan Tambora yang banyak menyimpan barang tapi tidak pernah digunakan. Di Scavenger Art Gallery nantinya penduduk lokal maupun luar daerah Tambora dapat mengikuti kelas workshop yang mengajarkan cara mengubah barang-barang yang sudah tidak terpakai tersebut menjadi sebuah karya seni yang bernilai dan bisa di pamerkan maupun di jual.

Zoning bangunan diatur dengan berdasarkan kondisi tapak dan jalan, massa diarahkan kearah persimpangan jalan KH Moh Mansyur dan jalan sawah lio sebagai bentuk kontekstual terhadap jalan. Area yang bersifat bising diletakan jauh dari area pemukiman agar mengurangi bising yang dapat mengganggu kenyamanan warga sekitar. Taman dan tempat retail makanan diletakkan di bagian basement untuk mereduksi tingkat kebisingan. Taman diletakkan di tengah berfungsi sebagai pengikat antar massa agar menjadi satu bagian yang saling terhubung. Sirkulasi pengunjung dibedakan dengan jalur servis yang terletak dibelakang agar tidak mengganggu pengujung dari arah lobi utama. Akses masuk ke tapak dapat diakses melalui 3 arah, utara timur dan selatan. Jalur pedestrian diutamakan dari jalan utama yang lebih ramai. Disediakan beberapa tempat parkir untuk kendaraan roda 4 dan 2 bagi pengunjung. 


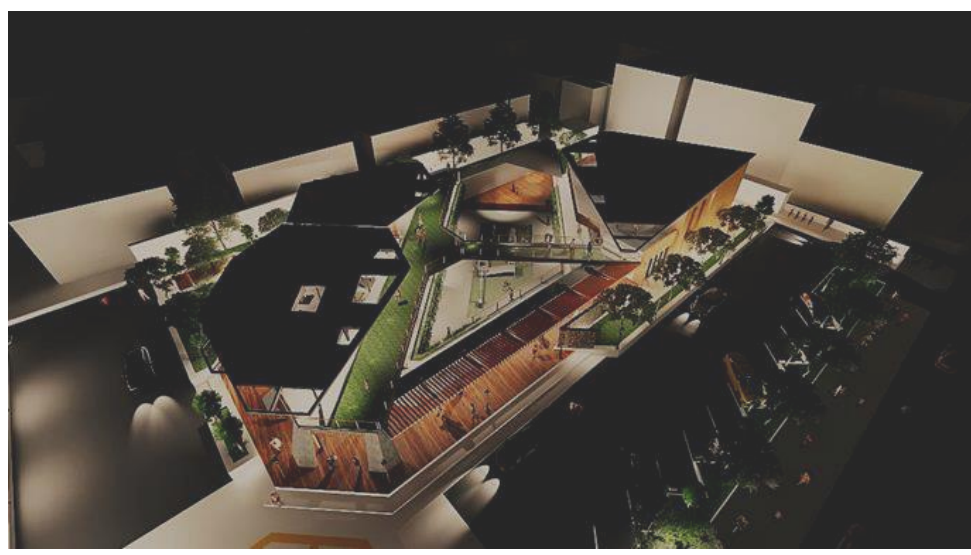

Gambar 9. Perspektif Eksterior

Sumber: Dokumen Pribadi

Pada bagian exterior gubahan akan terlihat berbeda dari bangunan sekitarnya yang dominan terhadap bentuk kotak. Hal ini untuk menunjukan bahwa bangunan ini memang beda dari bangunan yang lainnya, bukan hanya sekedar tempat makan, taman bermain dan pameran biasa. Inilah keunikan Scavenger Art Gallery yang mempunyai daya tarik tersendiri untuk mewadahi masyarakat sekitar. Konsep fasad atap memanjang didesain mengikuti iklim Indonesia yang cenderung hujan.material yang digunakan merupakan material lokal yang mudah didapat. Material bata merah ekspos membuat bangunan terkesan megah dan kokoh, menarik perhatian bagi orang yang melewati jalan KH Moh mansyur.
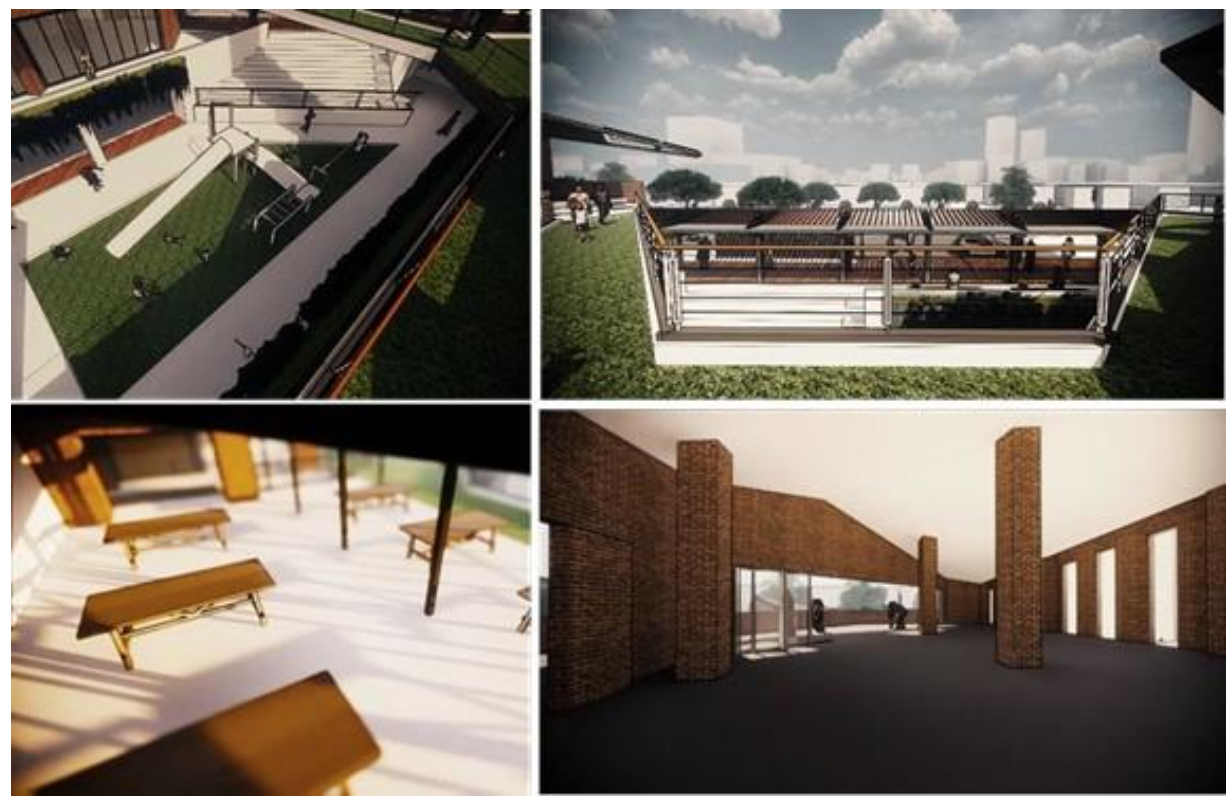

Gambar 10. Perspektif Interior

Sumber: Dokumen Pribadi

Suasana interior pada bangunan dibuat dengan konsep keterbukaan, dimana memanfaatkan banyak ruang luar agar membuat suasana luas/lapang yang berbeda dari suasana rumah penduduk yang cenderung sempit/sesak. Sifat ruangnya terbuka untuk memanfaatkan cross ventilation sebagai bentuk penghematan biaya. Dan pada ruang-ruang tertentu memakai ruang bebas kolom untuk kebutuhan seperti pameran, rapat, dan lain-lain. Pada bangunan ini juga dimasukan beberapa fasilitas penunjang seperti, area bermain anak, jogging track, front desk, dropoff lobby.Ada juga area komersil yang memjual berbagai macam souvenir hasil karya workshop dan juga material-material mentah untuk membuat karya seni.Desain interior bangunan memakai bahan bata merah dan kayu yang bersifat sederhana dan tidak menunjukan kesan mewah.Pada dasarnya bangunan ini ingin menampilkan karakter terbuka kepada kalangan mana tanpa membeda-bedakan. 


\section{KESIMPULAN DAN SARAN}

\section{Kesimpulan}

Disimpulkan Scavenger Art Gallery dengan ketinggian 2 lantai dan 1 basement berperan sebagai wadah bagi penduduk Tambora untuk meluangkan waktu dalam bentuk pameran seni. Didukung dengan berbagai program penunjang lainnya yang bersifat publik. Scavenger Art Gallery merupakan sebuah third place yang menjawab permasalahan kawasan dan mengangkat identitas kawasan Tambora.Proses desain dilakukan mulai dari pengamatan lokasi, analisa tapak dan sekitar, dan melakukan proses gubahan dari hasil analisa yang ada.

\section{Saran}

Diharapkan proyek ini dapat menjawab permasalahan yang ada di Tambora dan dapat meminimalisir permasalahan sampah yang ada. Kedepannya proyek ini bisa lebih dikembangkan khususnya dalam pengembangan program agar dapat menjalin kerjasama dengan berbagai macam third place yang ada di Tambora sehingga dapat memiliki keterikatan satu dengan yang lain.

\section{REFERENSI}

Setiawan, A. (2017). Produksi Ruang Sosial sebagai Konsep Pengembangan Ruang Perkotaan Kajian atas Teori Ruang Henry Lefebvre. Research Gate di Lancaster University, 1-12

Oldenburg, Ray. (1989). The Great Good Place : Cafés, Coffee Shops, Bookstores, Bars, Hair Salons, and Other Hangouts at the Heart of a Community. US : Da Capo Press.

Zeisel, J. (1987). Inquiry by Design: Tools for Environment-Behavior researchh. New York and Melbourne: Press Syndicate of the University of Cambridge.

Carmona, Matthew, Tim Heath, Steve Tiesdell, and Taner Oc. (2010). Public Places, Urban Spaces: The Dimensions of Urban Design Second Edition. London: Routledge.

Carr, S., Francis, M., Rivlin, L.G. and Stone, A.M. (1992), Public Space. Cambridge University Press: Cambridge.

Pemerintahan Jakarta (2018).Statistik Kecamatan Tambora .Diakses Diakses 24 Januari https://jakbarkota.bps.go.id/publication/2019/12/23/f748434994aa0b90dbdaed6a/statistik - daerah-kota-jakarta-barat-2019

Rachmi (2018). Kawasan Terpadat Seasia Tenggara. Dalam Artikel Poskota. Diakses 25 Januari 2020, dari https://poskota.co.id/2018/03/06/tambora-kawasan-terpadat-se-asia-tenggarapenataan-rw-prioritas/ 
